\title{
Situated Inference versus Conversational Implicature
}

\author{
Christopher Gauker \\ University of Cincinnati
}

\begin{abstract}
As Grice defined it, a speaker conversationally implicates that $p$ only if the speaker expects the hearer to recognize that the speaker thinks that $p$. This paper argues that in the sorts of cases that Grice took as paradigmatic examples of conversational implicature there is in fact no need for the hearer to consider what the speaker might thus have in mind. Instead, the hearer might simply make an inference from what the speaker literally says and the situation in which the utterance takes place. In addition, a number of sources of the illusion of conversational implicatures in Grice's sense are identified and diagnosed.
\end{abstract}

\section{Introduction}

In one of Grice's examples of conversational implicature, a motorist has run out of gasoline and is approached by a passerby who informs him, "There is a gas station around the corner". As Grice understands the case, the motorist will ask himself what the passerby must have had in mind and, presuming that the passerby is speaking cooperatively, will conclude that the passerby must have had in mind that the gas station is open and has gas to sell. Assuming that the passerby did indeed have that in mind and expected the motorist to recognize that fact in this way, the passerby can be said to have conversationally implicated that the gas station is open and has gas to sell. In general, a speaker conversationally implicates that $p$ only if the speaker expects that the hearer will recognize that the speaker thinks that $p$.

However, there is another way to explain the transaction between the motorist and the passerby. The motorist, we may suppose, accepts what the passerby literally says as true: there is a gas station around the corner. Further, the motorist observes that they are at a busy intersection in the middle of the day; so and 108 Cowley Road, Oxford OX4 1JF, UK. 
any gas station around the corner is likely to be open and have gas to sell. Hence the motorist infers that he can buy gas at the gas station around the corner. Further, the passerby need not have intended that the motorist would reason in any other way. On this version of events, the motorist may derive the useful information about where he can get gas without ever considering whether the passerby had in mind that the gas station was open and had gas to sell.

More generally, we may find that in all of the sorts of cases where Grice finds a conversational implicature, we might instead suppose only that the hearer draws an inference from what the speaker literally says and the external situation; there is no need to suppose that the hearer contemplates whether the speaker had those propositions in mind. In that case, there will be no reason to suppose that the speaker expects the hearer to contemplate whether the speaker had those propositions in mind either. In cases where communication is not so successful, there may be cause for the hearer to reflect on whether the speaker had certain propositions in mind, but then the expectations that the hearer finds in the speaker will not be expectations to the effect that the hearer will think about the speaker's state of mind but only expectations to the effect that the hearer will draw an inference from what the speaker explicitly says and the external situation.

My thesis is that the concept of conversational implicature is indeed dispensable in this way. To show this, I will proceed as follows: First, I will try to explain more precisely what a conversational implicature is supposed to be, characterize the concept of successful communication in a way that is adequate for our purposes, and identify more precisely the kind of criticism I intend to make. Next, I will examine a number of Grice's examples in detail and argue that they do not exhibit conversational implicatures. Since these will all be cases in which communication may be deemed successful, I will next have to argue that conversational implicature is no better demonstrated in cases where communication is not so successful. After that, I will expose some of the sources of the illusion of conversational implicature. In closing, I will comment on the relevance of this critique to the theory of literal meaning.

\section{Preliminaries}

\subsection{Conversational implicature}

According to Grice, participants in a conversation are presumed to conform to the Cooperative Principle, which says:

Make your conversational contribution such as is required, at the stage at which it occurs, by the accepted purpose or direction of the talk exchange in which you are engaged. $(1989,26)$

This principle carries a variety of submaxims, such as that one's contribution should be just as informative as is required, that one should avoid saying any- 
thing for which one lacks adequate evidence, that one should avoid ambiguity, and so on.

Grice defined conversational implicatures as a variety of implicatures, which is a concept that he apparently expected could be grasped independently. Unfortunately, where Grice explains conversational implicature, he does little to explain implicature simpliciter. Presumably, there is a connection between Grice's general concept of implicature and his theory of speaker's meaning. In a broad sense, one might be said to implicate that $q$ if and only if one means that $q$ by doing something, where the pertinent kind of meaning is that which Grice called utterer's occasion-meaning $(1989,90)$ and defined in terms of the speaker's intentions toward the hearer. Alternatively, implicature might be defined more narrowly so that one may be said to implicate that $q$ only if one means that $q$ in this sense but the proposition that $q$ is not what is said (about which I will say more shortly). In either case, the assumption that conversational implicatures are implicatures might already contain a disputable assumption to the effect that speakers must expect hearers to recognize that they expect hearers to stand in a certain relation to the proposition implicated; but I will not try to argue on that basis.

With the Cooperative Principle and the general concept of implicature in the background, Grice defines conversational implicature as follows:

A man who, by (in, when) saying (or making as if to say) that $p$ has implicated that $q$, may be said to have conversationally implicated that $q$, provided that (1) he is presumed to be observing the conversational maxims, or at least the Cooperative Principle; (2) the supposition that he is aware that, or thinks that, $q$ is required in order to make his saying or making as if to say $p$ (or doing so in those terms) consistent with this presumption; and (3) the speaker thinks (and would expect the hearer to think that the speaker thinks) that it is within the competence of the hearer to work out, or grasp intuitively, that the supposition mentioned in (2) is required. (1989, $30-31)$

Although in clause (2) of this definition Grice writes of what is necessary to ensure consistency with the Cooperative Principle, Grice cannot mean here only logical consistency. Presumably Grice's intent in (2) is that the assumption that the speaker thinks that $q$ is somehow supposed to explain the speaker's conformity to the Cooperative Principle, that is, show us that the speaker can be considered as conforming to the Cooperative Principle.

Although in clause (3) the speaker is only supposed to think it within the competence of the hearer to work out that (2) holds, Grice has to hold also that the speaker conversationally implicates $q$ only if the speaker expects the hearer to recognize that (2) does hold. This is evident from the parenthetical remark in (3). The hearer would not think that the speaker would think it within the competence of the hearer to recognize that (2) holds unless the hearer did recognize that (2) holds. So the speaker would not think that the hearer would think that 
the speaker thinks that it is within the competence of the hearer to recognize that (2) holds unless the speaker expected the hearer to recognize that (2) does hold. That the speaker has to expect the hearer to recognize that (2) holds is confirmed also in Grice's account of the thought process by which the hearer works out the presence of a conversational implicature, according to which the hearer is to think (in part): “... he could not be [observing the maxims of the Cooperative Principle] unless he thought that $q$; [and] he knows (and knows that I know that he knows) that I can see that the supposition that $q$ is required" (1989, 31).

Thus, the definition of conversational implicature might be more plainly formulated as follows:

A speaker conversationally implicates that $q$ by saying that $p$ if and only if he or she implicates that $q$, and (1) he or she may be presumed to be conforming to the Cooperative Principle in saying that $p$, and (2) the explanation of his or her conformity to the Cooperative Principle is that he or she thinks that $q$, and (3) he or she thinks that the hearer will recognize that it is his or her thinking that $q$ that explains his or her conformity to the Cooperative Principle.

Where there is a conversational implicature that $q$, there exists in the speaker the thought that $q$, and the presence of this thought explains the presumed cooperativeness of what the speaker explicitly says, and the speaker thinks the hearer can recognize this. Of course, Grice did not mean that the speaker has to intend that the hearer contemplates the Cooperative Principle as such, but only that the speaker has to intend that the hearer will recognize that the speaker's thinking that $q$ shows that the speaker's words have some feature that we theorists can recognize as one required by the Cooperative Principle.

In defining conversational implicature in this way, we are presuming that we can identify what a speaker says independently from our identification of conversational implicatures. It is not at all easy to define the concept of what is said. In lots of ways a person's actual words may fall short of an "eternal sentence", interpretable as expressing a definite proposition on the basis of lexicon and syntactic structure alone irrespective of the context of utterance. How much and what kinds of "filling in" are to be allowed in the specification of what is said? For present purposes it is not important to characterize the concept of what is said considered as a concept from folk linguistic theory. What matters is only how best to define the concept of what is said for purposes of explaining linguistic communication in terms of it-for instance, in order to define a useful notion of conversational implicature.

For present purposes, it is best to treat what is said as at least a complete proposition. It is the proposition that the speaker's words immediately express in light of the semantics of the speaker's words and the context of utterance (which might include the speaker's state of mind). So if John says, "I am sick", 
then what John says is the proposition that John is sick. If an auto mechanic says, "This will take some time," then what he says may be the proposition that replacing the drive axles will take at least two days. Given our definition of conversational implicature, perceived in the light of common examples, this is the right decision, because we do not want this kind of filling in to qualify as conversational implicature. Grice himself may have thought of the literal meanings of ironical and metaphorical utterances as excluded from what is said and as belonging only to what one "makes as if to say" (see 1989, 34), but since saying something and making as if to say something are taken together in his definition of conversational implicature, for present purposes we may safely lump them together.

As Grice defined conversational implicature, a speaker's conversational implicatures are in some respects independent of the speaker's expectations and intentions. In particular, the satisfaction of condition (2) is not simply a matter of what the speaker expects or intends. Though a speaker expects the hearer to think that the speaker thinks that $q$ and intends thereby to conversationally implicate that $q$, the speaker may fail to conversationally implicate that $q$ if in fact the supposition that the speaker thinks that $q$ is not necessary in order to explain the speaker's conformity to the Cooperative Principle. In some cases, there may be many ways of interpreting the speaker as conforming to the Cooperative Principle, and in that case the speaker will simply fail to conversationally implicate that $q$ even if he or she intends to do so. One might try to improve on Grice's definition by treating the proposition conversationally implicated as singled out in some other way than simply by being that which the speaker must have in mind given that the speaker is presumed to be speaking cooperatively. In that case, this further specification of the proposition conversationally implicated might appeal to the speaker's expectations and intentions, but it is not obvious that it would have to do so.

In principle one might put forward a definition of conversational implicature on which the presence of a conversational implicature is even more independent of the speaker's expectations and intentions than it is on Grice's definition. One might require not only, as in condition (3), that the speaker think that the hearer will recognize that it is his or her thinking that $q$ that explains his or her conformity to the Cooperative Principle, but also that this thought be reasonable. One might even go so far as to substitute the following more externalistic condition in place of Grice's own condition (3):

$\left(3_{\text {ext }}\right)$ The hearer will in fact recognize that it is the speaker's thinking that $q$ that explains the speaker's conformity to the Cooperative Principle.

That is, one might stipulate that there is a conversational implicature only where there is actual uptake on the part of the hearer. It will be useful to distinguish between Grice's own definition of conversational implicature and this more externalistic conception of conversational implicature, with $\left(3_{\text {ext }}\right)$ in place of (3), 
because, as I will explain more fully below, my critique will pertain first of all to the externalistic conception and will pertain to Grice's own conception only by extension. Doubts about the existence of conversational implicature externalistically conceived will extend to conversational implicature as Grice conceived of it because if successful communication does not depend on the hearer's recognizing that the speaker is thinking that $q$, then surely it also does not depend on the speaker's intending that the hearer recognize that the speaker is thinking that $q$.

\subsection{Successful communication}

As I will explain more fully in the next section, the question I wish to raise is whether it is necessary to posit conversational implicatures, as Grice defined them, in order to understand ordinary, noncontrived cases of successful linguistic communication. Accordingly, we will need at least some vague conception of successful linguistic communication that does not immediately commit us to the conclusion that it is. Even if we defined successful linguistic communication in such a way that conversational implicature would be a necessary component in some cases, my doubts could be raised; they could be raised as doubts about the possibility of successful linguistic communication in those cases. But since the sorts of cases at issue need not strike us as intuitively failures to communicate, it will be less confusing to formulate my doubts as doubts about the necessity of conversational implicature and seek some conception of successful communication that is compatible with these doubts.

Some seemingly reasonable definitions of successful linguistic communication would indeed lead by short steps to the conclusion that conversational implicature is often necessary. For example, suppose we assume that in choosing their words, speakers intend to cause their hearers to contemplate a variety of propositions and always expect that their hearers will discover which propositions they are to contemplate as a result of contemplating the motives underlying the speaker's choice of words. In that case, the theory of conversational implicature might seem almost inevitable as a way of accounting for at least some cases in which the propositions that the speaker intends the hearer to contemplate go beyond the proposition that the speaker's words literally express in the context.

A less tendentious way to define successful linguistic communication would be simply this: Successful linguistic communication is an episode in which a person uses language to successfully achieve a goal. Although this definition requires a couple of repairs, it is correct in not implying that there is any very special kind of goal that uniformly characterizes linguistic communication. In particular, it does not imply that all of the goals that linguistic communication might serve can be reduced to one, such as revealing to the hearer the content of the speaker's thought. The goal may be to produce some concrete result, such as finding food, or to inform the hearer, or just to show that one can state the answer to a given question. 
Typically, a speaker does have a goal, although it may not be one that the hearer shares. For example, the speaker may aim to persuade the hearer to take some action that the hearer does not wish to take. But even where the hearer does not share the speaker's primary goal, there will usually be a common goal at some level. $A$ may be trying to persuade $B$ that $p$, while $B$ is trying to persuade $A$ that not-p, and so to that extent they may be at odds; but even then they may have in common the goal of reaching agreement on the question whether or not $p$. They may engage in this debate without seriously expecting that either party will win, but even then, they must act as if they were trying to reach agreement.

In other cases, discourse may take place although there really is nothing that deserves to be called a goal, shared or otherwise. For instance, two people may chat quite aimlessly about things that happened during the day. So long as they speak fairly literally and explicitly, then perhaps, as speakers of the language, each may understand what the other is literally saying, as we might get something out of an accidental string of words that accidentally forms a grammatical sentence. But in order for us to distinguish between successes and failures beyond this, the interlocutors must at least feign a goal, such as deciding on a course of action or resolving a dispute.

A counterexample to the definition in terms of goals would be a case in which a person uses language to achieve a goal but in which it is irrelevant that the noises he or she makes belong to language (such as shouting "Get away!" to scare away a raccoon). In another, more difficult sort of counterexample the linguistic character of the noises is relevant but the speaker's goal is achieved in the wrong way. For example, suppose $A$ and $B$ both have it as their objective to find out which of two movies the other prefers to see and then to go with the other to see that one. Suppose A says, "So you don't want to see Titanic?" and $B$ replies simply, "Yes". A may assume that this reply means, yes, I do not want to see Titanic. B may have meant, yes, I want to see Titanic. But B may have meant this only because she assumed that $A$ wanted to see Titanic. The result is that $A$ and $B$ go to see the movie that both of them really preferred to see (not Titanic). Intuitively, this is not a case of successful linguistic communication; and yet it does depend on $B$ 's understanding of the language.

To avoid such counterexamples, let us simply define successful linguistic communication as an episode in which a person uses language to achieve a goal, the linguistic character of the act of speech is relevant, and the achievement of the goal does not depend on the hearer's misunderstanding the speaker's act of speech. This definition is a bit question-begging, but it will suffice for present purposes. It is question-begging insofar as we speak of misunderstanding and a definition of understanding might depend on a notion of successful linguistic communication. It is not entirely question-begging, however, since we can sometimes recognize misunderstandings apart from any general conception of the function of language. It will suffice for present purposes, because in fact no one will wish to object that in the examples that I will discuss the linguistic char- 
acter is irrelevant or that the achievement of the speaker's goal depends on a misunderstanding on the part of the hearer.

\subsection{The present thesis}

Let me zero in on my thesis by setting some upper and lower bounds. An upper bound would be the thesis that conversational implicatures, as Grice defined them, do not exist. This is a bit too strong since two people might contrive a situation in which the first promises to conform to the Cooperative Principle and the second has to guess what the first must have in mind given that the first is doing so and the first predicts that the second will be able to do this. So conversational implicatures are at least possible and may have actually occurred. A lower bound would be simply the thesis that some of the examples of conversational exchange that Grice or others have thought of as exhibiting conversational implicature fail to do so. More than that, I want to say that the paradigmatic cases fail to do so; and even more than that, I want to say that the concept of conversational implicature is not a useful concept in the theory of language.

My way of striking a middle ground will be to formulate my claim as the thesis that the concept of conversational implicature has no role to play in our understanding of normal cases of intelligent conversation. I assume that if we can explain a conversational exchange perfectly well without supposing that the conditions of Grice's definition of conversational implicature are fulfilled, then we should not believe that there is a conversational implicature in that case. By the theory of conversational implicature I mean the claim that the concept of conversational implicature does play a role in the explanation of normal linguistic communication. I intend to criticize the theory of conversational implicature in this sense by arguing that in paradigmatic cases we have no reason to believe that the conditions of the definition are fulfilled.

My way of arguing against the theory of conversational implicature starts with the hearer. Even in those sorts of conversations in which conversational implicatures have been supposed to be present, it is not necessary for the hearer to consider whether the speaker has a thought having the content that is supposedly conversationally implicated. If this is right, then, assuming that hearers will not generally do what they have no need to do, we may infer that the externalistic version of the third condition- $\left(3_{\text {ext }}\right)$ - is seldom satisfied. From this, we may in turn infer that condition (3) itself is seldom satisfied, because if there is no reason for the hearer to consider whether the speaker had such a thought, then there is no reason for the speaker to expect the hearer to do so. Of course, nothing prevents the hearer from contemplating what the speaker might have had in mind if the hearer happens to take an interest in that, and the hearer might have a special reason to take an interest in that where there appears to be some misunderstanding. But even if the hearer, for whatever reason, happens to take an interest in what the speaker had in mind, then, where $q$ is the proposition supposedly conversationally implicated, what the hearer will think the speaker 
intended is not that the hearer was to recognize that the speaker thinks that $q$, but that the hearer was to infer that $q$ from what the speaker literally said and the external situation.

So I am arguing against the supposition that certain thought processes take place in hearers and speakers, and I am arguing against this on the grounds that nothing is explained by the supposition that they do take place. No one should expect us to accept that one knows just by direct introspection while speaking that such thoughts take place. We will have a reason to think that such thoughts take place in ordinary cases only if the supposition that they do is part of the best explanation of the linguistic exchange in those cases-either of why it succeeds or of why it fails. My claim is that in all ordinary intelligent conversation, and in particular in the sorts of cases in which conversational implicatures have been supposed to play a role, we can perfectly well explain the linguistic exchange without positing such thoughts, and thus without positing conversational implicatures, at all.

Again, the central target of my critique is the idea that normally when the success of communication depends on the hearer's grasping some content over and above that which the speaker literally expresses, the hearer has to recognize that the speaker has a thought with that content; so I should stress here at the start that it really is essential to Grice's conception that in grasping a conversational implicature hearers must do this. One might think that, regardless of what Grice himself said, a useful notion of conversational implicature might remain if, in place of (3) and its externalistic variant, we substituted a condition merely to the effect that the hearer ought to be able to recognize that it is the speaker's thinking that $q$ that explains the speaker's conformity to the Cooperative Principle or a condition to the effect that, as Grice himself puts it, it is within the competence of the hearer to grasp that it is the speaker's thinking that $q$ that explains his or her conformity to the Cooperative Principle. But even if we made these moves, we could not maintain that the concept of conversational implicature had a role to play in the explanation of linguistic communication unless we supposed that in many typical cases hearers do that which, on these proposals, they ought to be able to do or have it within in their competence to do, and that means contemplating whether the speaker has in mind that $q$, where the proposition that $q$ is that which the speaker is supposed to be conversationally implicating. My arguments should equally cast doubt on any such thesis.

More generally, while I will take for granted that the concept of conversational implicature can be defined more or less as Grice defined it, my critique does not stand or fall with the details of Grice's analysis. As I have already explained, the externalistic conception of conversational implicature will be at issue here in addition to Grice's own conception. If somebody wishes to define conversational implicature in some other way, then it may turn out that my critique does not apply. In particular, if someone wants to define conversational implicature in a way that does not imply that what is conversationally impli- 
cated is something that the hearer normally or often takes to be a content of the speaker's thought, then my critique may not apply. But I think my critique does touch the theories of some others who, while criticizing Grice's own definition, wish to retain the term "conversational implicature" or at least "implicature". In particular, I think my critique pertains as well to Sperber and Wilson's theory and to Wayne Davis's theory.

Like Grice, Sperber and Wilson $(1987,1995)$ think of communication as a matter of speakers intending to convey certain propositions and hearers grasping those intentions. What they call ostensive-inferential communication is characterized by an informative intention, which, in their terminology, is the intention to make certain assumptions manifest to the hearer, and a communicative intention, which is the intention to make it mutually manifest between the hearer and the speaker that the speaker has this informative intention (1995, 50-64). They state flatly: "We see verbal communication as involving a speaker producing an utterance as a public interpretation of one of her thoughts, and the hearer constructing a mental interpretation of this utterance, and hence of the original thought" $(1995,230)$. Their difference with Grice concerns primarily the manner in which hearers are supposed to arrive at an interpretation. Rather than make inferences from Grice's Cooperative Principle, with its various submaxims, hearers are supposed to arrive at an interpretation by assuming that the correct interpretation is "consistent" with "the principle of relevance" (pp. $167 \mathrm{ff}$.), where the principle of relevance states that "every act of ostensive communication communicates a presumption of its own optimal relevance" (158), and the presumption of optimal relevance, in turn, is basically the presumption that the assumptions that the speaker intends to make manifest will be optimally relevant to the hearer $(1995,158){ }^{1}$

Similarly, Wayne Davis (1998) takes for granted that successful communication is a matter of the hearer's contemplating the content of the speaker's thought; so a speaker implicates something only if he or she intends the hearer to recognize that he or she has a thought with that content (p. 186). Davis's difference with Grice is that he thinks that the propositional contents that the speaker intends the hearer to recognize as implicatures cannot be calculated from the presumption that the speaker is speaking cooperatively in the way Grice imagines. He does not believe that some other characterization of the cooperative principle will solve the problem; indeed, cooperation need not be presumed at all. Speakers can mean various things by the things they say, and no independently recognizable variety of implicature may be picked out in terms of some special method of recognizing those implicatures, such as inference from the presumption of cooperation. Davis thinks that much of what is called conversational implicature involves a conventional element. One thing that shows this is that while a sentence of one language may be a literal translation of a sentence of another, an utterance of the first may not carry the same "implications" as an utterance of the second (p. 167). His book does not offer a positive account of how hearers recognize implicatures that are not plausibly conventional; rather, he seems to hand that question over to cognitive science (p. 131). 
I differ from these other critics in that I do not assume that successful communication requires the hearer to consider what propositions the speaker might have expected the hearer to grasp. These critics and I might also differ over whether this is necessary for a grasp of the speaker's literal meaning, or what the speaker "says", but that is not the issue here. ${ }^{2}$ Here the question is just whether, in the sorts of cases touted as paradigms of conversational implicature, in order for the hearer to grasp the additional content that the hearer has to grasp over and above what he or she literally says, it is necessary for the hearer to consider that the speaker has a thought with that content. Sperber and Wilson and Davis believe it, whereas I deny it.

I should not be interpreted as arguing for any alternative definition of conversational implicature. It will be a mistake to take my alternative accounts of the examples and on the basis of those attribute to me an alternative definition of conversational implicature. For instance, it would be a mistake to conclude, on the basis of my treatment of the petrol example, that I am claiming that a person conversationally implicates that $p$ if and only if he or she intends the hearer to infer that $p$ from the truth of what he or she says and the external situation. Such intentions might have a place in a theory of communication, but I do not see any reason to view them as a defining a special class of meanings. (Reasons to define a special class of meanings, beyond literal meanings, will be discussed in section 5 below.) As I have explained, my thesis is just slightly weaker than the thesis that conversational implicatures simply do not exist.

\section{Examples}

Three purported examples of conversational implicatures from Grice's "Logic and Conversation" (reprinted in Grice 1989) will now be discussed in detail. In each case, we will find that there is no need to suppose that clause (3) of the definition of conversational implicature is satisfied. We will find that given a plausible account of the objectives of the conversation, we can account for the success of the conversation without supposing that the hearer considers what assumptions the speaker must have been making if the speaker is to be regarded as speaking in conformity to the Cooperative Principle and therefore without supposing that speakers expect hearers to do this. Insofar as something more than what the speaker literally says must be grasped in order for the communication to be successful, we can account for that fact by supposing that the hearer makes an inference from the external situation and what the speaker literally says. ${ }^{3}$ In each case, I will have to tell the story in more detail than Grice did, but I do not think that my way of telling it prejudices the case against Grice's interpretation.

The critique of these three examples will show that what has seemed obvious about examples of conversational implicature is not obvious after all. It will not show that there are no other examples of conversational implicature, but it should lead one to critically re-examine any other purported examples before presuming that they really are examples. I do not claim that everything that has 
ever been thought of as Gricean conversational implicature is subject to specifically similar criticisms. My view is that the phenomena that have been called conversational implicature bear various similarities and differences to one another, but there is nothing that unites them and distinguishes them from other things. (For instance, the sorts of cases that Davis identifies as involving a conventional element may require a different treatment.) But the cases I will consider here are the paradigms, and so if my critique of these is successful, it will not be too much of an exaggeration to claim, as I have, that the concept of conversational implicature is entirely dispensable in this way.

\subsection{The petrol example}

Consider again the example with which I began. As Grice tells the story, $A$ is standing by an obviously immobilized car and is approached by $B$. The following exchange takes place:

\section{A: I am out of gasoline. \\ $B$ : There is a gas station around the corner.}

(I have substituted the words "gasoline" and "gas station" for Grice's words "petrol" and "garage".) As Grice explains it, " $B$ would be infringing the maxim 'Be relevant' unless he thinks, or thinks it possible, that the [gas station] is open, and has [gasoline] to sell; so he implicates that the [gas station] is, or at least may be open, etc." (1989, 32).

The ultimate goal of this conversation is to enable $A$ to drive his car again. $B$ 's more immediate goal, we might suppose, is to bring it about that $A$ goes around the corner and gets gasoline at the gas station there. To explain the success of communication in this case, we have to explain how $A$ is able to conclude from what $B$ explicitly says that he can get gas at the gas station around the corner. One explanation for $A$ 's drawing this conclusion might be Grice's own explanation of this, namely, that $A$ recognizes that this is what $B$ must be supposing if $B$ is conforming to the Cooperative Principle. An alternative explanation is that $A$ reasons from the truth of what $B$ says and the character of the external situation to the conclusion that if there is a gas station around the corner then probably it is open and has gas to sell. Thoughts about what the speaker must have been thinking need not play any role whatsoever, and the speaker need not have intended the hearer to have any such thoughts. In my view, this is in fact the better explanation.

Suppose the circumstances are these: $A$ and $B$ are near a busy intersection near a heavily populated part of town in the middle of the day. In a place like this, one rarely finds the abandoned remains of a former gas station, with boarded up windows and the empty frame of a Texaco sign. Any gas station at a location like this one is likely to be a thriving concern. Most people would know this. So in order for $A$ to conclude that the gas station will be open and have gas, $A$ need only understand and accept what $B$ says, namely, that there is a gas 
station around the corner. In order for $B$ 's words to succeed, it is not necessary for $A$ to consider whether $B$ is conforming to the Cooperative Principle beyond assuming that $B$ is speaking the truth in English, and it is not even necessary for $A$ to consider whether $B$ does think that the gas station is open. $B$ might indeed intend that $A$ will conclude that the gas station is open and has gas to sell (or maybe not), and in order for $A$ to reach this conclusion $A$ will have to pay attention to various features of the situation beyond what $B$ explicitly said; but there is no special reason for $A$ to pay attention to what $B$ might have had in mind in speaking, and $B$ need not intend $A$ to do so. There are various other conclusions that $A$ might draw from what $B$ explicitly says, such as that he can buy a bag of chips at the gas station; the reason he does not draw these conclusions is not that they are not what $B$ had in mind but just that he is not interested in these matters.

To see the relevance of the external circumstances, imagine that the circumstances are different. Suppose the exchange takes place on a remote country road in the middle of the night. Nonetheless, there really is a gas station around the corner, it is open and has gas to sell. $B$ 's ultimate goal is still to bring it about that $A$ goes around the corner and gets gasoline at the gas station there. So success in this case would still amount to $A$ 's concluding that he can get gas at the gas station around the corner. But communication would probably not succeed. $A$ will not conclude that the gas station is open and has gas to sell. Even if he asks himself why $B$ might say this, how it could possibly be relevant to his predicament, $A$ will not draw this conclusion-at least not without further questioning. If $A$ asks himself why $B$ spoke as he did, he might conclude that $B$ was simply thinking out loud as he contemplated the issue. Alternatively, when $A$ considers what $B$ had in mind, $A$ might consider that $B$ might have expected him to infer that he could get gas at the gas station around the corner, but even if so, the expectation he considers attributing to $B$ need not be the sort of expectation that Grice takes to be characteristic of conversational implicature but only the expectation that $A$ will draw an inference from what he, $B$, literally said and the external situation in which the utterance takes place (an expectation which, as it happens, is not reasonable).

This is not to say that $A$ would not walk around the corner to the gas station. He might, after all, ask $B$ whether the gas station is open and receive an affirmative answer. But suppose $B$ is driving by and does not stop but simply shouts out the window, "There's a gas station around the corner". Even then, A might, in desperation, walk around the corner to see if, against all odds, someone is there to give him gas; but the reason for his doing this will not be his presuming, on the basis of what was said to him, that the gas station is open. His reason will be that if there is even a small chance that someone is there, it is worth his effort to check it out. His reason would be just the same if in the moonlight he could faintly make out a darkened gas station sign off in the distance.

Perhaps there is some tendency to think about the case as follows: If $B$ had not wished to be cooperative, he might have said "There is a gas station around 
the corner" knowing full well that it was closed. In that case, if $A$ tries to get gas around the corner, his doing so is in some sense an error. So to avoid this error $A$ ought to consider whether $B$ is being cooperative and ought to infer that he can get gas around the corner only if the answer is that, yes, $B$ is being cooperative and so thinks that the gas station is open. But this is a fallacy. If some people take a canoe trip and the dam on the river breaks, they might say afterward that it would have been helpful to check the soundness of the dam before setting out. But it does not follow that, if in fact the dam does not break, they should nonetheless have considered whether the dam was about to break. In general, a person cannot be expected to consider every eventuality that might have proven relevant, but only those that circumstances give the person some special reason to consider.

Participants in a conversation may indeed assume that their interlocutors are speaking cooperatively. That is, they may assume that to be so unless something special happens that ought to raise a doubt. There is a difference between assuming that the speaker is speaking cooperatively and not assuming that a speaker is speaking uncooperatively, but I do not wish to deny even that hearers may normally assume that speakers are speaking cooperatively. However, in conceding this I am conceding nothing to Grice's theory of conversational implicature. To suppose that the hearer will normally assume that the speaker speaks cooperatively is not in itself to assume that the hearer contemplates the speaker's state of mind, for to speak cooperatively is to say something relevant to the situation, and the hearer may assume that the speaker's words are relevant without making any assumptions about the speaker's state of mind. Without conceding anything to Grice, I could even grant that hearers assume that speakers intend to speak cooperatively. An assumption about a speaker's intention is an assumption about a state of mind, but it is not the assumption about the speaker's state of mind that is in question here. What Grice requires is specifically that the speaker expect that the hearer will recognize that it is the speaker's thinking that $q$, where the proposition that $q$ is the content that is supposed to be conversationally implicated. $A$ might assume that $B$ intends to speak cooperatively without assuming that it is $B$ 's thinking that the gas station is open that reconciles $B$ 's assertion with the assumption that $B$ is speaking cooperatively and without considering whether $B$ thinks that the gas station is open at all.

\subsection{The South of France example}

In another of Grice's examples, $A$ is planning with $B$ an itinerary for a vacation in France. "Both know that $A$ wants to see his friend $C$, if to do so would not involve too great a prolongation of his journey" $(1989,32)$. The following dialogue takes place:
A: Where does $C$ live?
$B$ : Somewhere in the South of France. 
According to Grice, $B$ implicates in this case that he does not know what town $C$ lives in; his answer to $A$ is not as informative as would be desired, and $B$ expects $A$ to recognize that he, $B$, is being less informative than would be desired because he does not know more precisely where $C$ lives.

In this example, $A$ 's goal is to find out whether he can visit $C$ on his trip to France. This is crucial. In other circumstances, $B$ might answer as he does not because he does not know more precisely where $C$ lives but because he does not think $A$ would recognize the name of the place. Or $B$ might see that it will be useful to $A$ to know exactly where $C$ lives only if $C$ lives somewhere on the East Coast of the United States; so given that $C$ does not live there, a more precise specification of $C$ 's location would be irrelevant. Or $B$ may know that $A$ plans to travel somewhere in Europe but may not know more specifically where; thus $B$ answers "Somewhere in the South of France" anticipating that if $A$ then says that he will be in the South of France, then he, $B$, will go on to offer more precise information.

As Grice describes the case, we are not given any reason to think that $A$ ought to consider whether $B$ is saying as much as he can about $C$ 's location without going beyond what he has reason to believe. $B$ 's answer to $A$ takes $B$ some distance toward his goal of finding out whether he can visit $C$ but does not take him all the way. It is not built into the story that $A$ has some further goal that would be achieved only through $A$ 's recognizing that $B$ is failing to be more informative because a more informative answer would go beyond what $B$ has reason to believe. $A$ need not have the goal of deciding whether $B$ is being as informative as he might be; $A$ may simply give no thought to $B$ 's motives. If $B$ 's answer does not satisfy $A$ 's need to know, $A$ may turn to someone else for more information without taking any time to consider whether $B$ has said as much he knows. So there is no automatic reason for $B$ to expect, let alone intend, that $A$ will consider whether $B$ is being as informative as he might be and no reason for $B$ to expect that $A$ will think that $B$ thinks that he, $B$, does not know more precisely where $C$ lives. $B$ might also not expect that $A$ would suppose that $B$ possesses more precise information that he is withholding; but $B$ 's not expecting that $A$ will think that $B$ is withholding information is not the same as $B$ 's expecting that $A$ will recognize that $B$ is lacking information.

What these remarks show is that Grice's example will not constitute an example of conversational implicature unless the story is told in such a way that it is clear that $B$ may expect that $A$ will consider whether $B$ knows more specifically where $C$ lives. So imagine that $A$ has some reason to wonder whether $B$ might be withholding more precise information about $C$ 's location. $A$ knows that $B$ is in love with $C$ and views $A$ as competition, and $B$ knows that $A$ knows that. $C$ has recently moved to France to escape this jealous wrangling, and $B$ may really not know where she is. In this case, it is plausible that $A$ would question whether $B$ is being as informative as he might be and conclude that in fact he is, that is, that $B$ believes he does not know more specifically where $C$ lives. Moreover, since $B$ might recognize that $A$ has this question, $B$ might expect that 
$A$ will conclude that $B$ is telling as much as he knows about $C$ 's location and thus that $B$ does not know more precisely where $C$ lives. However, this is still not enough to establish a conversational implicature. If what is conversationally implicated is supposed to be that $B$ does not know more precisely where $C$ lives, then $A$ has to recognize that it is $B$ 's thinking that he does not know more precisely where $C$ lives that explains $B$ 's conformity to the Cooperative Principle and, in this case, establishes that $B$ is saying as much as he can without going beyond what he has reason to believe; or, at least, $B$ has to expect that $A$ will recognize this. In fact, $A$ does not have to consider whether $B$ thinks this about his own state of knowledge, and $B$ does not have to expect $A$ to do so, as I will now explain.

In order for $A$ to achieve his goal of deciding whether $B$ might be withholding more precise information about $C$ 's location (in my more elaborate version of the story), it is enough that $A$ conclude somehow that $B$ does not know more precisely where $C$ lives; $A$ does not have to draw that conclusion on the basis of the assumption that $B$ is cooperating in Grice's sense and does not have to consider whether $B$ thinks that he, $B$, does not know more precisely where $C$ lives. If $A$ can recognize that $B$ believes that he does not know more precisely where $C$ lives, then he can recognize it on the basis of what he, $A$, knows about $B$ and $C$ and the circumstances, including other things $B$ might say to $A$. For example, $A$ might have reason to believe that $B$ has been trying to track $C$ down and so far has been unable to do so. If $A$ could not infer in some such way that $B$ does not know more precisely where $C$ lives, then, in light of his doubts about $B$ 's motives, the assumption that $B$, in saying "Somewhere in the South of France", was conforming to the Cooperative Principle would not help, for in that case $A$ could not assume that $B$ was in fact being cooperative. So the thought that it is $B$ 's thinking that he, $B$, does not know more precisely where $C$ lives that explains $B$ 's conformity to the Cooperative Principle need not figure into the thinking by which $A$ answers his question about $B$ 's state of knowledge, and there is no other reason for $A$ to consider whether $B$ thinks that he, $B$, does not know more precisely where $C$ lives. So likewise, there is no reason for $B$ to expect that $A$ will consider this.

\subsection{The letter of recommendation}

"A is writing a testimonial about a pupil who is a candidate for a philosophy job, and his letter reads as follows: 'Dear Sir, Mr. X's command of English is excellent, and his attendance at tutorials has been regular. Yours, etc.'” (1989, 33). In this example (which is fascinating to graduate students), Professor $A$ is supposed to conversationally implicate that Mr. $X$ is no good at philosophy. The example differs from the previous two in that the speaker (writer) is deliberately not saying what he knows although he is in some way called upon to say it. I think that for the example to be plausible the letter has to do a better of job of explaining the candidate's good points; otherwise, the reader might infer that the writer is simply a nincompoop whose opinion does not reflect on $\mathrm{Mr}$. $X$ at all; so let us imagine we are dealing with such a letter. 
If we posit a conversational implicature in this case, then we do so as part of an explanation of how Prof. $A$ achieves his communicative goal in writing this letter. So it is relevant to consider what that goal might be. We cannot assume that Prof. $A$ intends the reader to believe that Mr. $X$ is no good at philosophy. A judicious reader could not be so influenced by a single letter of this sort, and Prof. A will know this. At the same time, it would not be right to say that Prof. A's objective in writing the letter is only to cause its readers to believe that Prof. A believes that Mr. $X$ is no good at philosophy. This bit of information about Prof. $A$ would have no value in itself, but is valuable only inasmuch as it is some evidence, to be weighed alongside other evidence, that Mr. $X$ is in fact no good at philosophy. (The distinction between wanting one's audience to believe something and wanting one's audience to believe that one believes something also comes up in discussions of Grice's theory of meaning something by something, but I am not discussing that issue here.) Thus, if the proposition that Mr. $X$ is no good at philosophy is supposed to be something that Prof. $A$ does conversationally implicate, as opposed to being something he unwittingly leaves readers to infer, then what he must intend is that, as a result of reading his letter, readers will at least come to regard that proposition as one that the letter somehow supports. So the question is whether we can explain in some other way, without invoking conversational implicature, how it comes about that a reader comes to regard the proposition that $\mathrm{Mr}$. $X$ is no good at philosophy as at least supported.

In fact, there is no reason why, in order to reach this conclusion, readers of the letter need to consider whether Prof. $A$ 's belief that Mr. $X$ is no good at philosophy explains Prof. $A$ 's conformity to the Cooperative Principle, nor indeed need readers consider whether Prof. $A$ does believe that $\mathrm{Mr}$. $X$ is no good at philosophy; accordingly, there is no reason for Prof. $A$ to expect that readers will do this. Readers may simply reason as follows: "This is a letter of recommendation for a candidate for a philosophy job. The letter does not say anything about whether the candidate is good at philosophy. Therefore, there is some reason to doubt whether this candidate is good at philosophy." If the reader reflects on his or her inference from the fact that the letter does not say that the candidate is good at philosophy to the conclusion that there is some reason to doubt whether he is, then the reader may reason as follows: "The purpose of a letter of recommendation is to describe the candidate's qualifications for the job. Being good at philosophy is obviously a relevant qualification for a philosophy job. So the fact that the letter does not say this is some reason to think that the candidate is not." Thus, the information pertinent to the reader's goals, namely, whether Mr. $X$ is good at philosophy, is acquired by an inference from the situation and what the speaker actually says. The pertinent feature of the situation is simply that the document is a letter of recommendation. Accordingly, Prof. A has no reason to expect to achieve his aim in any other way.

In reply it might be said that the reasoning I have attributed to the reader requires the support of some further assumptions about the writer. If the reader is justified in assuming that this letter will do what letters of recommendation 
are supposed to do, then the reader must assume that the letter writer is conforming to the Cooperative Principle. If the reader assumes that the letter does what it ought to do in addressing Mr. $X$ 's qualifications for a philosophy job, the reader must assume that in not saying that $\mathrm{Mr}$. $X$ is good at philosophy Prof. $A$ was in fact being cooperative, because Prof. $A$ believes that $\mathrm{Mr}$. $X$ is no good at philosophy. Thus the reader must, at least implicitly, recognize that it is Prof. $A$ 's thinking that Mr. $X$ is no good at philosophy that explains his conformity to the Cooperative Principle. And Prof. A, anticipating that the reader will recognize this, will qualify as having conversationally implicated that $\mathrm{Mr} . X$ is no good at philosophy.

My reply to this reply is that, while the reader's reasoning about Prof. A's state of mind might in this way might strengthen the conclusion that Prof. $A$ thinks that Mr. $X$ is no good at philosophy if the reader had independent evidence that Prof. $A$ wished to be cooperative and consequently attempted to list all of $\mathrm{Mr}$. $X$ 's relevant characteristics, typically the reader of the letter would have no other basis for supposing that Prof. $A$ wished to be cooperative and thus had described all of Mr. $X$ 's relevant characteristics than the fact that the description of $\mathrm{Mr} . X$ occurred in the context of a letter of recommendation for a philosophy job. But if the facts about the contents of the letter and the conclusion that Prof. $A$ is speaking cooperatively support the conclusion that Mr. $X$ is no good at philosophy, and the sole basis for the conclusion that Prof. $A$ is speaking cooperatively is that the letter is a letter of recommendation, then the conclusion that $\mathrm{Mr} . X$ is no good at philosophy is equally well supported by the fact that the letter is a letter of recommendation with this content quite apart from the intermediate conclusion that Prof. $A$ is speaking cooperatively. Therefore, the reader's contemplation of what Prof. A might have had in mind given cooperativeness can typically add nothing to the force of the reader's conclusion. Borrowing a term from probability theory, we can say that the premise that the description occurs in a letter of recommendation screens off the premise that the writer is being cooperative.

\section{Incompletely successful communication}

In all of the examples considered above, linguistic communication was basically successful. Thus it might be objected that it is the selection of exclusively successful cases that has put the theory of conversational implicature at a disadvantage. When a linguistic exchange goes smoothly, the thought processes involved may be somehow masked. Accordingly, I will now consider a variety of ways in which communication may be less than completely successful and argue that cases of unsuccessful exchange do not provide any further reason to posit conversational implicatures in Grice's sense.

\subsection{No success}

In cases where either the speaker or the hearer is seriously mistaken about the nature of the external situation, so that the hearer cannot draw the conclusions from the external situation and what the speaker says that the speaker intends 
the hearer to draw, there may still be propositions beyond those literally said that the speaker intends to convey. For example, in the petrol example, if the conversation takes place in a remote place at night, but $B$ is confused about the time and location and thinks that anyone should be able to recognize that a gas station around the corner would be open and have gas to sell, $B$ might intend $A$ to grasp the proposition that the gas station is open and has gas to sell. How in general are we to characterize the propositions that the speaker intends to convey in such cases? We cannot characterize them as propositions that the hearer can infer on the basis of the external situation and what the speaker literally says, since, in view of the mismatch between what the speaker and the hearer take for granted about the external situation, the hearer may not in fact be able to do that. So perhaps we should think of them as propositions that the speaker conversationally implicates or intends to conversationally implicate.

On the contrary, in cases where communication is unsuccessful because the proposition that the speaker intends to convey beyond that which the speaker literally said is not one that the hearer can infer on the basis of the speaker's words and the external context, we may simply say that the proposition that the speaker intended to convey was one that the speaker intended the hearer to infer on the basis of the speaker's words and the situation. In the variant on the petrol example in the previous paragraph, the reason the communication is unsuccessful is that the conclusion that the speaker expects the hearer to draw on this basis is a conclusion that the hearer cannot in fact draw, and the reason for this is that what the speaker takes for granted about the external situation is not what the hearer takes for granted about it. In other cases, the failure may be due to the hearer's misunderstanding what the speaker literally says or due to the hearer's making a bad inference.

\subsection{Accidental success}

Without an inference to what the speaker has in mind, it might be said, any success in communication is at best accidental. Consider the following variation on the petrol example. Suppose, as in the initial version, that it is reasonable for $A$ to reason from the external situation and what $B$ says to the conclusion that the gas station is open and has gas to sell. But this time, suppose that $B$ imagines that he is living in a wasteland where all the stores have gone out of business and believes that everyone he encounters knows this as well. When $B$ says, "There is a gas station around the corner", $B$ thinks of himself as being ironic, as if he could go on to say, "but of course you'll never get any gas there". Not knowing this about $B, A$ goes around the corner and buys gas. In this case, we could say that the goals of the conversation are achieved only accidentally. Although $A$ drew a helpful conclusion, the success was accidental because $A$ did not draw that conclusion in the right way. He either did not consider what $B$ had in mind, or if he did consider that, he drew a conclusion about $B$ 's thought that $B$ did not intend him to draw.

On the contrary, the reason why the success of the communication in this case is merely accidental is that the speaker did not properly perform his part 
in a cooperative verbal exchange. While both the hearer and the speaker share in the responsibility for successful communication, it is the speaker's part to choose his or her words in such a way that the hearer will perform as the speaker intends as a result of reasoning only from the external situation and what the speaker says, and the hearer does his or her part if he or she reasons well from the external situation and what the speaker literally says. A hearer cannot normally discern a speaker's thought process except insofar as the speaker chooses his or her words in such a way that the hearer may assume that, in reasoning from what the speaker says and the external situation, he or she is reasoning as the speaker intended (which is not to say that the hearer must actually contemplate what the speaker intended). So it would not be reasonable to declare an episode of communication accidental just because the reasoning of the hearer was not adequately in touch with the thought of the speaker. The reason the success is only accidental in the present variant on the petrol example is that the speaker did not properly do his part. Due to the speaker's unreasonable beliefs about the hearer, the speaker chose words from which a reasonable person would draw conclusions that the speaker did not intend the hearer to draw.

\subsection{Thin success}

Success in linguistic communication comes in various thicknesses. A thick success would be success in getting the hearer to perform some overt action that the speaker intended the hearer to perform. A somewhat less thick but still not very thin success would be success in bringing the hearer to share a certain belief with the hearer. A very thin success would be merely getting the hearer to recognize that the speaker has a certain belief. The presence of a Gricean conversational implicature may seem to be clearest in cases where the only kind of success that can be claimed is very thin, and from its presence in thin cases we might infer its presence in thick cases too.

For example, suppose that Jane tells Mireille that her advertising agent has been seen with Mireille's business competitor. Jane is insinuating that Mireille's advertising agent is working for Mireille's competitor. More precisely, Jane intends to plant in Mireille's mind the thought that possibly the agent and the competitor are working together. Mireille, however, knows that that is nonsense. Mireille knows that her agent and her competitor are simply friends who occasionally meet to socialize. So Jane does not have the thick success of getting Mireille to share her suspicions, but she does, we may suppose, have the thin success of getting Mireille to recognize that she, Jane, has those suspicions. How does Jane's speech act succeed in the thin sense? Perhaps Mireille asks herself, in effect, "Why is Jane saying this to me?" The answer she gives herself may be something like, "Because she thinks that what she is telling me, namely, that my agent and my competitor have been seen together, will be interesting to me, and the reason she thinks that is that she thinks it is evidence that my agent is doing advertising work for my competitor." This is not an explicit application of the principle that conversation will be cooperative in Grice's sense, but the presumption that Jane intends to say something of interest to Mireille may be 
construed as a corollary. So we may conclude that Mireille does in fact recognize that it is Jane's thinking that Mireille's advertising agent is working for Mireille's competitor that explains how Jane's speech is in conformity with the Cooperative Principle.

In section 2.1 I drew a distinction between Grice's own conception of conversational implicature and a more externalistic conception. I think that the story of Jane and Mireille gives us a plausible example of conversational implicature in the externalistic sense, but not an example of conversational implicature according to Grice's own conception. It is an example of conversational implicature in the externalistic sense if, as I have allowed, Mireille recognizes Jane's suspicions on the basis of the presumption that Jane is conforming to the Cooperative Principle. However, the story of Jane and Mireille does not give us a case of conversational implicature in Grice's sense because it is not the case that Jane expects that Mireille will recognize her thought on the basis of the presumption that Jane is being cooperative. Rather, Jane expects Mireille to think that her agent may be working for her competitor on the basis of an inference from what she, Jane, is telling her and everything else that Mireille knows about her agent and her competitor. Thus, this example illustrates my claim in section 2.3 that in those cases where the hearer does inquire into the speaker's state of mind, what the hearer will find is not that the speaker intended the hearer to recognize that the speaker thinks that $q$, where $q$ is the proposition supposedly conversationally implicated, but that speaker intended the hearer to infer that $q$ from what the speaker literally said and the external situation.

In any case, this example gives us no reason to think that there is conversational implicature in cases where linguistic communication is successful in a thicker sense. If in light of everything else Mireille knows, Jane's assertion does cause Mireille to worry that possibly her agent is doing work for her competitor, then Jane's assertion may have that effect on Mireille without Mireille's having to first consider whether Jane suspects that the agent is doing work for the competitor. Mireille may consider whether Jane suspects this if she pauses to consider why Jane has told her this. But instead she may forget all about Jane and rush off to confront her advertising agent. In that case, there would be no conversational implicature even in the externalistic sense. Moreover, Jane should not expect to have her effect on Mireille in any other way. As the story is told, she should not expect Mireille to consider what she, Jane, had in mind; so we do not have a case of conversational implicature in Grice's sense either. More generally, we should not assume that every case of thick success in linguistic communication amounts to piling up all that might be involved when successes are much thinner.

\section{Sources of illusion}

The arguments for the theory of conversational implicature that I have seen never go beyond interpreting a few examples in terms of it. Since, as we have seen here, the examples are not persuasive, there must be something else that leads 
people to accept the theory. I think many philosophers will maintain that arguments really are not necessary because it is just intuitively obvious that there is such a thing as conversational implicature and the only problem is to define it. But I think this intuition is at best a natural illusion. In this section, I will identify and criticize several possible sources of this illusion.

\section{1. "What was meant"}

Many times hearers find themselves unable to see the relevance of what a speaker literally says. They cannot perceive its relevance even after taking into account the situation in which it takes place. In that case, they may request a clarification. These requests for clarification may take various forms. The hearer might ask the speaker, "What do you mean?" or "What are you trying to say?" or even "What do you have in mind?" In some cases, the hearer may locate the failure to understand in some particular feature of the speaker's utterance, and in that case the hearer might ask a question like, "What do you mean by unwilling?" or "Who were you referring to when you said everyone?"

Thus our requests for clarification, in view of the words used in formulating them, seem to inquire into the speaker's state of mind. Even when we make our requests using words like "mean" or "refer" we are usually not talking about a feature of the speaker's utterance but about the speaker's act of uttering it, as if we were seeking an account of its motivation. In view of this, it is certainly natural-one could say, common sense — to think that when hearers need no such clarifications, that is because they already have the answers to such questions. They already know the propositional content that the speaker intends the hearer to grasp. And when a speaker communicates more than he or she literally says, what must be happening is that somehow the hearer recognizes what the speaker has in mind beyond what the speaker literally says.

It is possible to explain these formulations of requests for clarification without supposing that successful communication always requires the hearer to consider what the speaker might have had in mind (specifically, whether the speaker had in mind that $q$, where the proposition that $q$ is what the speaker is supposed to have meant). The proper occasions for such requests are occasions on which coordination by means of language has broken down. The aim of these requests is to set the conversation back on track, to get the speaker to start over and this time say something more helpful. The way to do this is to ask the speaker to reflect on what he or she is trying to achieve and in that way to find a more effective means of achieving it, and that is why our requests for clarification may take the form of requests to the speaker to reflect on his or her intentions in speaking. Where communication proceeds smoothly, without the hearer's having to intervene in any way in the speaker's choice of words, the hearer need not thus inquire into the speaker's state of mind in speaking (specifically, into whether the speaker had it in mind that $q$, where the proposition that $q$ is what the speaker is supposed to have meant).

We should not expect our ordinary ways of talking about language to reveal the basic concepts that we should employ in a viable theory of how language 
works. So the fact that our ordinary talk about language is talk about what people mean by what they say should not all by itself persuade us that a theory of language must take the form of an account of meaning something by something. It is not unreasonable, in developing a theory, to start with common sense, but we should never be especially confident that common sense is a good source for theory or that we have understood what common sense seems to say.

\subsection{Meaning and responsibility}

Aside from these ordinary uses of the "means" locution, there is a more philosophical usage. For each of the conclusions that may be drawn from an act of speech, a philosopher may ask, "Is that part of what the speaker meant?" The presumption is that there is a special relation of meaning between a speaker and a proposition that we ought to try to define. One motive for thinking this is the wish to appeal to such a relation in distinguishing between those propositions toward which the speaker has a special responsibility as a result of speaking and those toward which the speaker has no such responsibility. A speaker's special responsibility toward a proposition may include the responsibility for giving reasons to believe the proposition, and this responsibility may entail that the speaker may be deemed blameworthy if the proposition proves false. In ordinary language this distinction may be represented in various ways, but in philosophy one might try to represent it as a distinction between what is meant and what is not.

Grice's theory of conversational implicature might seem useful in explicating the pertinent relation of meaning. Roughly, a speaker means a proposition-in the way that gives the speaker a special responsibility toward that propositionjust in case the proposition is one that the speaker either literally expressed or conversationally implicated, for these are the propositions that the speaker intends the hearer to recognize as contents of the speaker's thought on the basis of the speaker's choice of words. Thus, in the petrol example, if $A$ goes around the corner and finds that the gas station is abandoned, $A$ might have cause for complaint against $B$ on the grounds that what he conversationally implicated was not true.

Of course, there is no simple relation between responsibility and intention. It is not true that we hold people responsible only for those effects that they intend; we also hold people responsible for things they do not intend but merely foresee and even sometimes for things they do not foresee but should have foreseen. Still, what a person intends may form the core, or minimum of what a person can be held responsible for, and so the theory of conversational implicature might play a role in identifying that core of the responsibilities that a speaker acquires through speaking. But even supposing that conversational implicature in Grice's sense were a common occurrence, we could not maintain that the only conclusions a speaker might intend his or her hearer to draw on the basis of his or her act of speech would be those that the speaker intended the hearer to recognize either as literal meanings or as conversational implicatures. For instance, from the fact that someone is talking to me on the telephone at 6:00 p.m. I might 
infer that she is working late, and she might intend me to draw that conclusion and bear responsibility for my drawing that conclusion, but that she is working late is neither a literal meaning nor a conversational implicature of her act. So it is doubtful whether there is any special role for the concept of conversational implicature to play in defining speaker responsibility.

Suppose nonetheless that some special role in defining speaker responsibility is identified for the sorts of content that are deemed conversational implicatures in the usual sorts of examples. Suppose, for instance, that in the petrol example the proposition that the gas station around the corner is open and has gas to sell is one of a class of contents that occupies a special place in our theory of speaker responsibility. Even then it is not obvious that the best way to identify this class of contents would be in terms of the concept of conversational implicature. Instead we might identify those contents as conclusions that the speaker intends the hearer to draw on the basis of what the speaker literally says and the other features of the situation that the speaker expects the hearer to be aware of.

\subsection{Interpretation as explanation}

I have argued that in purported cases of conversational implicature it is not necessary for the hearer to consider whether the speaker thinks that $q$, where $q$ is the content that is supposedly conversationally implicated; it is sufficient for the hearer to make an inference from the external situation and what the speaker says. Against this it may be said that I am expecting the hearer to proceed blindly, that is, to act without considering the speaker's motivation in speaking or, more generally, the causes of his or her speech. An act of speech, it may be said, can have the intended effect on a hearer only insofar as the hearer treats it as evidence for something-only insofar as the hearer can infer from its occurrence that certain other events, its causes, must have occurred as well.

Taken in one way, the idea that hearers can normally explain the speaker's act of speech is wrong, but taken in another way it is right. It is wrong if the idea is that a speaker, in choosing his or her words, has a conception of a state of mind that he or she wishes to produce in the hearer and designs a sentence that, as a consequence of the thought processes he or she expects to take place in the hearer, will produce that state of mind and that in order to understand the speaker the hearer must reconstruct this deliberation on the part of the speaker. It is an exaggeration to say that the hearer must normally interpret blindly; certainly interpretation involves the application of some kind of knowledge of language that pairs utterances in context with effects. Still, the hearer must normally interpret without reconstructing any such plan on the part of the speaker. If the hearer tried to infer the speaker's state of mind in this way and the speaker tried to plan his or her speech with a view to the hearer's reconstruction of the speaker's plan, and neither proceeded at any stage blindly, then each would be consumed in an infinite regress, as I will now show. 
Let us consider how this happens just from the hearer's point of view. The way in which the speaker falls into regress will be analogous. According to our hypothesis, the hearer presumes that the speaker's choice of words is part of a plan to produce a certain mental state in the hearer, and the speaker designs his or her act of speech with a view to the hearer's reconstruction of the speaker's plan. Thus the hearer, in working out the speaker's plan, will have to consider the speaker's expectations regarding the hearer's reconstruction of the speaker's thought process. But the speaker knows this, and so, in working out the hearer's reconstruction of the speaker's plan, will have to consider the hearer's expectations regarding the speaker's expectations regarding the hearer's reconstruction of the speaker's plan. But the hearer knows this, and so, in working out the speaker's plan, will have to consider the speaker's expectations regarding the hearer's expectations regarding the speaker's expectations regarding the hearer's reconstruction of the speaker's plan. And so on. Thus the hearer can never work out the speaker's plan, because no such bottomless series of conditions can be fulfilled.

Nonetheless, the idea that hearers can normally explain speakers' acts of speech is right if the idea is just that hearers can normally presume that speakers have a conception of the goals of the conversation and speak as they do in order to promote the achievement of those goals. While a competent speaker must have the ability to speak in a way that will often promote the achievement of the goals of the conversation, a speaker does not normally have any conception of how his or her words will do that, and a hearer does not normally ascribe any such conception to a speaker. A choice of words will be a good choice if it enables the hearer, by means of an inference from the external situation and what is literally said, to do his or her part toward the achievement of the goals of the conversation. It is not necessary for a speaker to be aware of, or even to reason unawares from, such a criterion so long as he or she does in fact operate more or less in accordance with it. Consequently, it would not normally be correct for the hearer to suppose that the speaker spoke as he or she did as a result of reasoning from such a criterion. Taken in the right way, then, the idea that the hearer can explain the speaker's act of speech does not support the notion that the hearer's understanding of an act of speech is a result of his or her discerning its underlying motivation.

This is not to deny that in special cases, the hearer may become aware that something has gone wrong in a discourse and seek a more specific explanation of the speaker's act of speech. In particular, if the hearer is unable to infer anything relevant from the external situation and the speaker's act of speech, then the hearer may try to figure out what misunderstanding or ulterior motives might have led the speaker to speak as he or she did. But as I have already observed in section 5.1, from the fact that a hearer may seek a special explanation of the speaker's act of speech in cases of miscommunication, we ought not to infer that hearers regularly seek a special explanation of the speaker's act of speech even when communication goes smoothly; and even in those cases where the 
hearer does seek an explanation, the hearer need not attribute to the speaker intentions of the sort that Grice describes.

\section{Implications for literal meaning}

The theory of conversational implicature may serve as a model for a theory of literal meaning. As defined, the concept of conversational implicature rests on the concept of what is said, which is associated with literal meaning; so there is no prospect of defining literal meaning in terms of conversational implicature. Grice's own procedure was to first define utterer's occasion-meaning and then in terms of that to define both literal (or in his terms timeless) meaning and conversational implicature. Still, Grice's theory of conversational implicature provides a paradigm for a more general theory of the manner in which a person indirectly conveys to another the content of his or her thought. Indeed, the examples that he deployed in constructing his theory of utterer's occasionmeaning were not very different from those he took to be cases of conversational implicature. (Consider, for example, the case in which someone draws a picture of Mr. $Y$ “displaying undue familiarity to Mrs. $X$ ” $(1989,218)$.) Thus, literal meaning might be conceived as arising from a process in which such indirect means of meaning something become conventionalized in some sense. In this way, one might conclude that for Grice conversational implicature was really the paradigm of meaning.

Even if one does not build a theory of the literal meanings of words on the example of conversational implicature in this way, there is another way in which a theory of literal meaning might be made to rest on the concept of conversational implicature. As I noted in section 2.1, very few utterances of sentences can be interpreted apart from the situation in which they occur. In order to interpret an utterance as expressing a particular proposition-the one "literally" expressed, it is necessary to consider it in light of the situation. The process by which this is done may be, and has been, conceived on analogy with the identification of conversational implicatures (Sperber and Wilson 1995, Bach 1994). Speakers are supposed to intend their hearers to grasp a certain proposition on the basis of the speaker's choice of words and the situation. The speaker's intention is itself an element of the situation and, one might say, it is the primary element of the situation to which the hearer has to attend in working out the proposition literally expressed.

The present critique of the theory of conversational implicature may serve as a model for a critique of these theories of literal meaning. Just as reflection on the speaker's underlying thoughts in speaking need be no part of the process by which hearers normally draw relevant conclusions from the external situation and what the speaker literally says, so too reflection on the speaker's underlying thoughts need be no part of the process by which hearers normally ascertain what a speaker is literally saying. We may even find that there is no good reason to think of communication as a matter of hearers determining which proposition the speaker's words may be interpreted as expressing. ${ }^{4}$ 


\title{
Notes
}

\begin{abstract}
${ }^{1}$ Although in these ways Sperber and Wilson seem to assume that communication essentially depends on a hearer's contemplating the speaker's intentions, their account (in 1995, Chapter 3) of how the hearer is supposed to draw relevant conclusions from the speaker's words gives no special role to the hearer's contemplation of the speaker's intentions. In this respect, I think the Sperber and Wilson theory is not entirely coherent. The reference to speaker's intentions is absent from the reformulation of the presumption of optimal relevance that Sperber and Wilson present in the postscript to the 2nd edition (p. 270), which might suggest that they had changed their minds about the nature of communication, but the rationale that they offer for the reformulation is not that the reference speaker's intentions was otiose, and they do not in any other way signal such a major change in outlook.

${ }^{2}$ For my own position on this, see my 1994, especially chapter 2 .

${ }^{3}$ What I am calling the external situation must not be identified with what might called the context of utterance, which is a parameter in semantic evaluation. For example, in deciding whether a sentence such as "Everyone is present" is true, we have to consider the contextually determined domain of discourse and the contextually determined referent of "present".

${ }^{4}$ This research was supported in part by a grant from the Taft Memorial Fund of the University of Cincinnati, which I gratefully acknowledge. A much abbreviated version of this paper was presented at a meeting of the American Philosophical Association in December, 1998. I thank my commentator on that occasion, Zoltán Szabó, for stimulating discussion of these issues, which influenced the fuller treatment in this paper. I also thank Michael Peirce, Brian Weatherson, Marina Sbisà and William Lycan for their contributions.
\end{abstract}

\section{References}

Bach, Kent. (1994) "Conversational Implicature," Mind and Language 9: 124-62.

Davis, Wayne A. (1998) Implicature: Intention, Convention and the Principle in the Failure of the Gricean Theory, Cambridge University Press.

Gauker, Christopher. (1994) Thinking Out Loud: An Essay on the Relation between Thought and Language, Princeton University Press.

Grice, Paul. (1989) Studies in the Way of Words, Harvard University Press.

Sperber, Dan and Deirdre Wilson. (1987) "Précis of Relevance: Communication and Cognition," Behavioral and Brain Sciences 10: 697-754.

Sperber, Dan and Deirdre Wilson (1995) Relevance: Communication and Cognition, 2nd edition, Blackwell Publishers. 